\title{
Enfermedad por arañazo de gato con compromiso óseo: Una forma atípica de presentación clínica
}

\author{
Magdalena Rodríguez C., Gustavo Giachetto L., Alejandro Cuneo E., \\ María del C. Gutiérrez B., Mario Shimchack R. y M. Catalina Pírez G.
}

\section{Cat-scratch disease with bone compromise: Atypical manifestation}

Fever, headache, myalgias and lymphadenopathy are characteristic manifestations of cat-scratch disease but other less common findings are described in 2 to $10 \%$ of cases. We report two children that presented with hepatosplenic abscesses and bone involvement. One child, had multiple areas of increased uptake in the bone scintigram with a positive serology ( $\operatorname{IgG}>1 / 256$, IgM slightly positive). The second child had destruction of the L2 vertebral body that compromised the channel and right foramen as visualized by MRI. In both cases, bacilli were observed in the bone biopsy by Warthing-Starry stain.

Key words: Bartonella hensealae, Cat-scratch disease, children.

Palabras clave: Bartonella hensealae, Enfermedad por arañazo de gato, niños.

\section{Introducción}

$\mathrm{L}$ a enfermedad por arañazo de gato (EAG) es una enfermedad infecciosa, benigna y autolimitada. Constituye la primera causa de linfadenopatía crónica benigna en el niño y en el adulto joven ${ }^{1}$.

La primera descripción se atribuye a Henri Parinaud en 1889. En 1931, Robert Debré reconoce el gato como vector de la enfermedad y la denomina "Cat-scratch disease". En 1985, fue identificado el agente etiológico, Rochalimaea henselae, reclasificada posteriormente como Bartonella henselae, un bacilo gramnegativo de crecimiento lento ${ }^{2}$.

La transmisión ocurre por arañazo, mordedura o lamedura de gatos pequeños ( $78 \%$ cachorros), rara vez de perros (menos de $5 \%$ ), monos o por lesiones con espinas. Aproximadamente $90 \%$ de los pacientes tienen historia de exposición a gatos, frecuentemente menores de un año, aparentemente sanos, con pulgas. Estas últimas actúan como vectores de la enfermedad entre gatos ${ }^{1}$.

En pacientes inmunocompetentes, la presentación clínica típica se caracteriza por fiebre, cefaleas, mialgias y adenopatía regional satélite al sitio de inoculación siete a 10 días después del arañazo de gato. Con relativa frecuencia las adenopatías se ubican en las extremidades superiores, cabeza y cuello y, en $80 \%$ de los casos, constituye la única manifestación de la enfermedad. La adenopatía evoluciona a la supuración en 25 a $30 \%$ de los casos. En 5 a $25 \%$ de los casos se describen formas atípicas de presentación, con compromiso sistémico. Dentro de éstas se encuentran el síndrome óculo-glandular de Parinaud, la afectación hepato-esplénica, ósea y encefálica, así como el eritema nodoso, eritema marginado, vasculitis, púrpura trombocitopénica, anemia hemolítica, endocarditis, neumonía atípica, neuritis óptica y corio-retinitis focal ${ }^{1,3-5}$.

Los criterios diagnósticos clásicos que permiten establecer el diagnóstico de la enfermedad son: existencia de contacto con gato; linfadenopatías regionales satélites al sitio de inoculación, con pruebas de laboratorio que permitan descartar otras etiologías; pruebas serológicas positivos para $B$. henselae; e histología característica (bacilos teñidos con tinción argéntica de Warthin-Starry y linfadenitis granulomatosa supurada) ${ }^{1,3}$.

Se presentan el caso de una niña de 12 años y un varón de 13 años que concurren al Hospital Pediátrico del Centro Hospitalario Pereira Rossell por fiebre prolongada realizándose los diagnósticos de EAG con compromiso hepato-esplénico. Ambos agregan en la evolución compromiso óseo; la niña a focos múltiples y el varón sólo vertebral.

El objetivo de esta comunicación es describir dos casos con una forma de presentación clínica no habitual de EAG, analizar la conducta terapéutica y evolución.

\section{Caso clínico 1}

Escolar femenina de 12 años, procedente de Colonia. Portadora de hipotiroidismo diagnosticado a los 8 años de edad, tratado con levotiroxina $(75 \mathrm{mg} /$ día), actualmente con función tiroidea normal. Buen crecimiento y desarro-
Ministerio de Salud Pública, Montevideo, Uruguay Hospital Pediátrico del Centro Hospitalario Pereira Rossell, (ACE, MSR)

Universidad de la República, Montevideo, Uruguay Facultad de Medicina Instituto de Pediatría (MRC, GGL, MCGB, MCPG).

Recibido: 18 de junio de 2008 Aceptado: 24 de marzo de 2009

Correspondencia a: Gustavo Alberto Giachetto Larraz pediatra@fmed.com.uy 
1lo. Inmunizaciones completas según el programa nacional. Antecedentes epidemiológicos: contacto con gatos.

Ingresó con historia de 10 días de evolución febril, hasta $40{ }^{\circ} \mathrm{C}$ axilar, diaria, de predominio matinal, mialgias y cefaleas, sin otra sintomatología. En el examen físico se apreciaba en buen estado general y fiebre de $40{ }^{\circ} \mathrm{C}$ axilar. Se describió una pústula en el tercer dedo de la mano izquierda y una adenopatía axilar ipsilateral de 3 x $2 \mathrm{~cm}$, dolorosa, móvil, firme. Choque de la punta en el $5^{\circ}$ espacio intercostal, línea medio clavicular, ritmo regular de 110/min, soplo sistólico 3/6 en el ápex, sin irradiaciones. Pulsos normales. Presión arterial 100/60 $\mathrm{mmHg}$. Esplenomegalia leve. El resto del examen físico era normal.
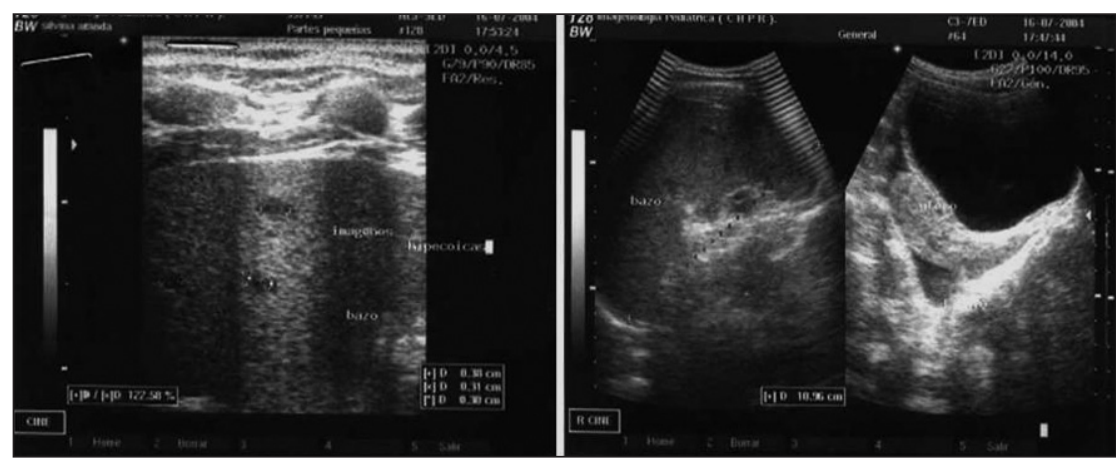

Figura 1. Ecografía abdominal. Múltiples imágenes hipoecoicas redondeadas a nivel esplénico.

Figura 2. Cintigrama óseo caso 1. Múltiples imágenes hipercaptantes (hombro, articulación coxofemoral izquierda, sacroilíaca izquierda, rama ascendente izquierda del maxilar inferior.

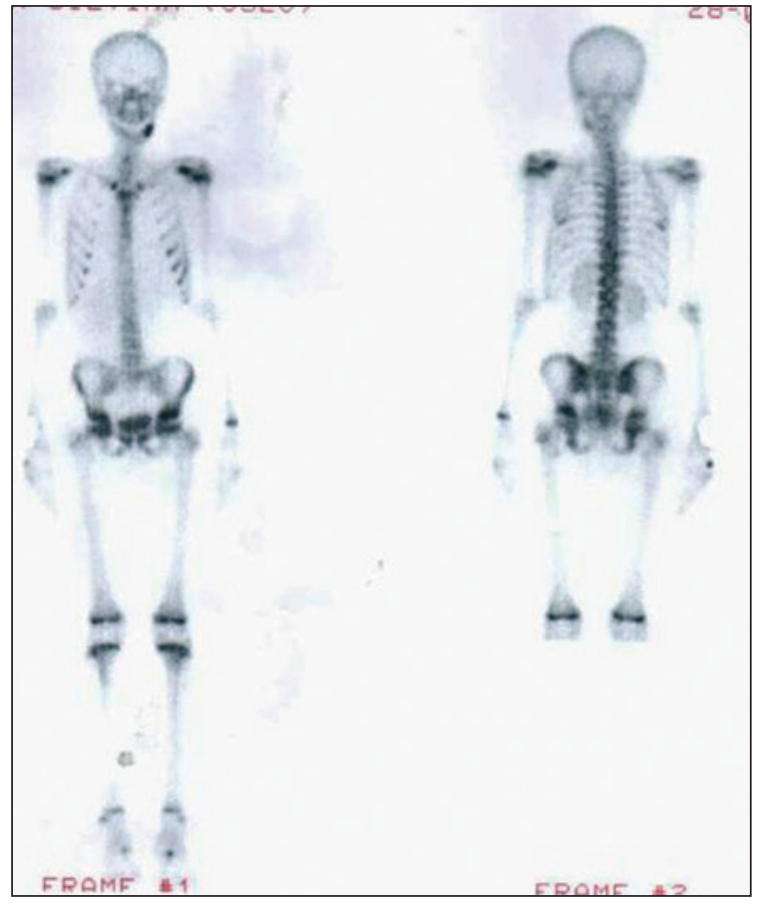

Exámenes de laboratorio: leucocitos $5.200 / \mathrm{mm}^{3}$ (segmentados $63 \%$, linfocitos $35 \%$ ), hemoglobina $11,6 \mathrm{~g} / \mathrm{dl}$, hematocrito $38 \%$, plaquetas normales; VHS: $18 \mathrm{~mm} / \mathrm{h}$ y hemocultivos (2) negativos. La ecografía abdominal mostró esplenomegalia $(10 \mathrm{~cm})$ con múltiples imágenes hipoecogénicas de 3 a $4 \mathrm{~mm} \mathrm{c} / \mathrm{u}$. Electrocardiograma y ecocardiograma con doppler normales. Se indicó tratamiento con azitromicina $10 \mathrm{mg} / \mathrm{kg} /$ día v/o durante 5 días y se otorgó el alta a las 48 horas. En la evolución persistió febril. Al $9^{\circ}$ día se agregó dolor intenso en el trocánter mayor del fémur y hombro izquierdos y una tumoración dolorosa de 7 por $3 \mathrm{~cm}$ en la séptima costilla izquierda. Fue reingresada con los siguientes parámetros de laboratorio: leucocitos $6.800 / \mathrm{mm}^{3}$ ( $60 \%$ neutrófilos), hemoglobina $12,6 \mathrm{~g} / \mathrm{dl}$, plaquetas $413.000 / \mathrm{mm}^{3}$; proteína $\mathrm{C}$ reactiva (PCR) 47,5 mg/l. En la ecografía abdominal esplenomegalia leve $(12 \mathrm{~cm})$ con múltiples imágenes hipo-ecogénicas redondeadas, de hasta $6 \mathrm{~mm}$ de diámetro; hepatomegalia leve (Figura 1). El cintigrama óseo mostró hipercaptación en el hombro, articulación coxo-femoral, articulación sacro-ilíaca izquierda y rama ascendente izquierda del maxilar inferior (Figura 2). Se le realizó una TAC de tórax que mostró destrucción segmentaria de la $7^{\mathrm{a}}$ costilla, con área de osteolisis y calcificación central (Figura 3).

La serología específica para $B$. henselae por inmunofluorescencia indirecta, realizada en el Hospital de

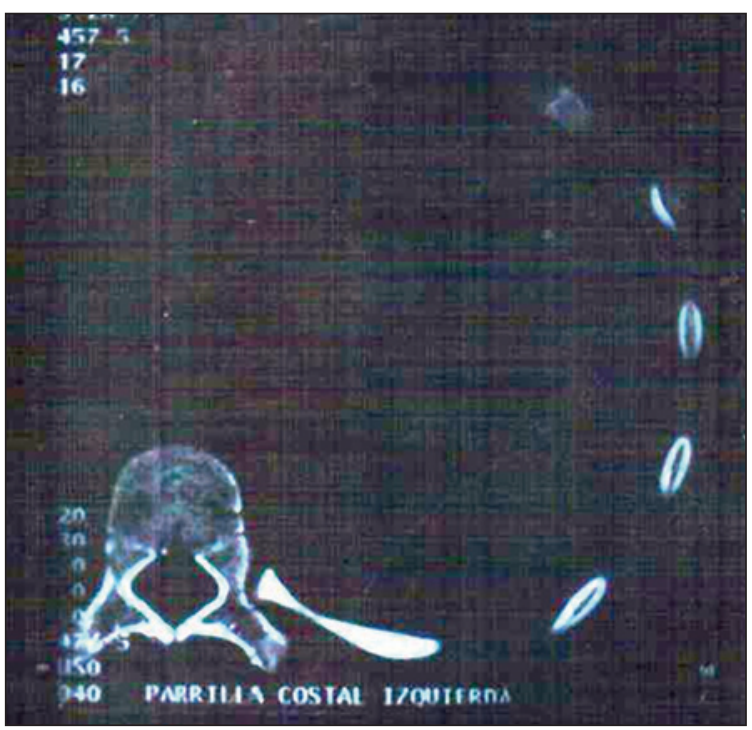

Figura 3. Tomografía axial computarizada de tórax. Ostéolisis segmentaria de $7^{\mathrm{a}}$ costilla. 


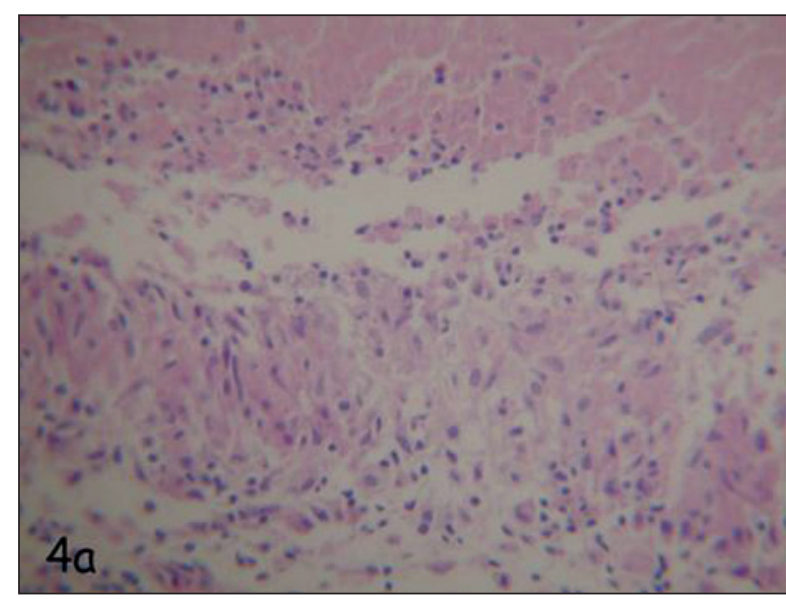

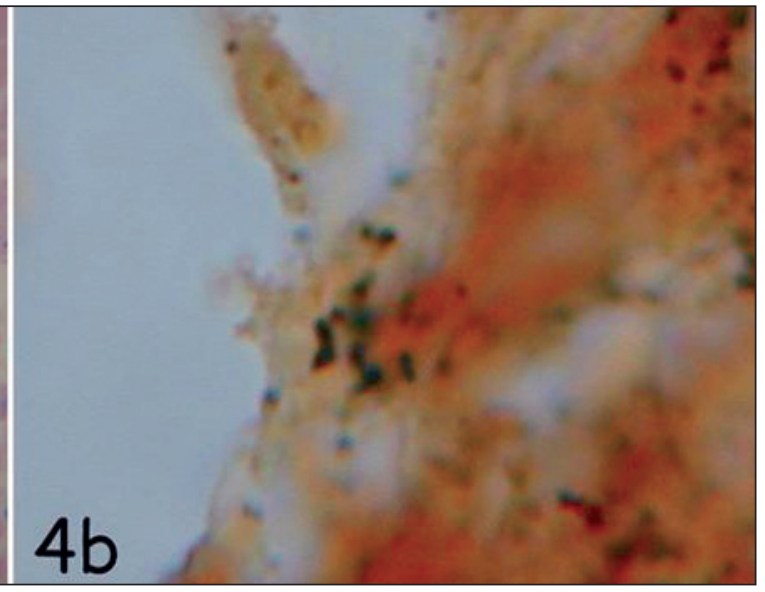

Figura 4. A: Biopsia ósea del caso 1. Se observa granuloma necrosante con empalizada de histiocitos ( $\mathrm{H}-\mathrm{E}$ 400x). B: Coloración de plata de Warthin-Starry; se observan bacilos fragmentados y deformados (900x).
Niños Dr. Ricardo Gutiérrez de Buenos Aires, fue positiva (IgG > 1/256, punto de corte $1 / 64$; IgM positiva).

En la biopsia de costilla se observó un proceso inflamatorio crónico con granulomas necrosantes. La tinción de Warthin-Starry permitió identificar bacilos de morfología compatible con B. henselae (Figura 4). Recibió tratamiento con ciprofloxacina $20 \mathrm{mg} / \mathrm{kg} /$ día i/v durante 11 días más rifampicina $10 \mathrm{mg} / \mathrm{kg} /$ día v/o por 16 días, y analgesia con metamizol y tramadol. Persistió febril durante 42 días. El dolor óseo y la limitación funcional articular regresaron en 18 días. Se otorgó el alta hospitalaria con buen estado general, afebril y sin secuelas.

\section{Caso clínico 2}

Escolar de 13 años, sexo masculino, oriundo de Montevideo. Buen crecimiento y desarrollo. Sin antecedentes mórbidos. Calendario de inmunizaciones completo. Ingresó por cuadro febril con 20 días de evolución, hasta $38^{\circ} \mathrm{C}$ axilar. A las 48 horas de iniciada la fiebre se instaló una lumbalgia permanente, progresiva, sin irradiaciones, con componente nocturno, que se exacerbaba con los movimientos. Al ingreso tenía limitación a la movilidad de la columna tóraco-lumbar y en la deambulación. No presentaba compromiso esfinteriano. Había consultado en forma ambulatoria donde le fuera indicada amoxicilina por 7 días y a continuación cotrimoxazol durante 48 horas. El examen físico a su ingreso evidenció un buen estado general, con mialgias, febril $38,5{ }^{\circ} \mathrm{C}$ axilar, sin lesiones en la piel ni mucosas o adenopatías. La columna presentaba rigidez y limitación total de la movilidad a la flexión: actitud escoliótica del tronco, con desvío axial de $1 \mathrm{~cm}$ a izquierda. Dolor a la palpación de las masas musculares paravertebrales. Abdomen simétrico, dolor a la palpación del hipogastrio, sin signos de irritación peritoneal ni visceromegalias. Fosas lumbares normales.
El resto del examen físico era normal.

Exámenes de laboratorio: leucocitos $9.900 / \mathrm{mm}^{3}$ (neutrófilos $4.800 / \mathrm{mm}^{3}$, linfocitos $3.700 / \mathrm{mm}^{3}$ ), hemoglobina $11,1 \mathrm{~g} / \mathrm{dl}$, hematocrito $38 \%$, plaquetas $407.000 / \mathrm{mm}^{3}$; PCR $7,6 \mathrm{mg} / 1$. En el hemocultivo se desarrolló Staphylococcus coagulasa negativa. La radiografía de columna del ingreso mostró una escoliosis sin alteraciones estructurales, sin componente rotacional (Figura 5). El cintigrama óseo evidenció una lesión hiperémica leve, en fase precoz, en la $2^{\mathrm{a}}$ vértebra lumbar (Figura 6). La resonancia magnética (RM) mostró un proceso sustitutivo del cuerpo de la $2^{\mathrm{a}}$ vértebra lumbar con compromiso del canal medular y foramen derecho, con indemnidad de los discos intervertebrales (Figuras 7-9). Se realizó una biopsia por punción del pedículo derecho de dicha vértebra. La anatomía patológica informó proliferación polimorfa con linfocitos, polimorfonucleares y escasos eosinófilos; hallazgos compatibles con osteomielitis. El cultivo bacteriológico de la muestra de biopsia fue negativo.

Se inició tratamiento con cefuroxima ev $100 \mathrm{mg} / \mathrm{kg} / \mathrm{día}$ el que mantuvo durante 23 días; vancomicina $40 \mathrm{mg} / \mathrm{kg}$ / día por 3 días, ceftriaxona $100 \mathrm{mg} / \mathrm{kg} /$ día durante 8 días y finalmente rifampicina $10 \mathrm{mg} / \mathrm{kg} /$ día más ciprofloxacina $20 \mathrm{mg} / \mathrm{kg} /$ día por 11 días. En total recibió 45 días de tratamiento antimicrobiano.

Se realizó una TAC de abdomen que mostró imágenes hipodensas en el hígado, compatibles con micro-abscesos. Frente a este hallazgo se solicitó efectuar una tinción argéntica con técnica de Warthin-Starry de la biopsia vertebral, lográndose detectar la presencia de bacilos gramnegativos con morfología compatible con $B$. henselae (Figura 10). En la evolución persistió con dolor lumbar y fiebre durante 30 días. Se otorgó el alta hospitalaria estando afebril y con movilidad prácticamente normal de la columna vertebral. La PCR y el hemograma se normalizaron en la evolución. 


\section{Caso Clínico}
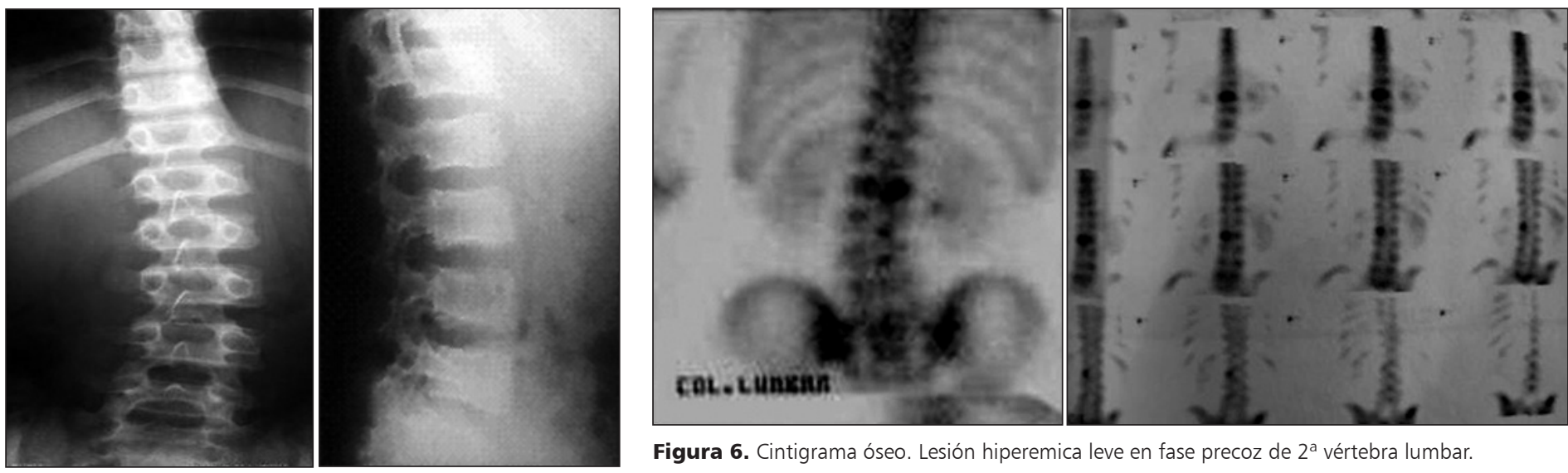

Figura 6. Cintigrama óseo. Lesión hiperemica leve en fase precoz de $2^{a}$ vértebra lumbar.

Figura 5. Caso 2: Radiografía de columna frente y perfil.

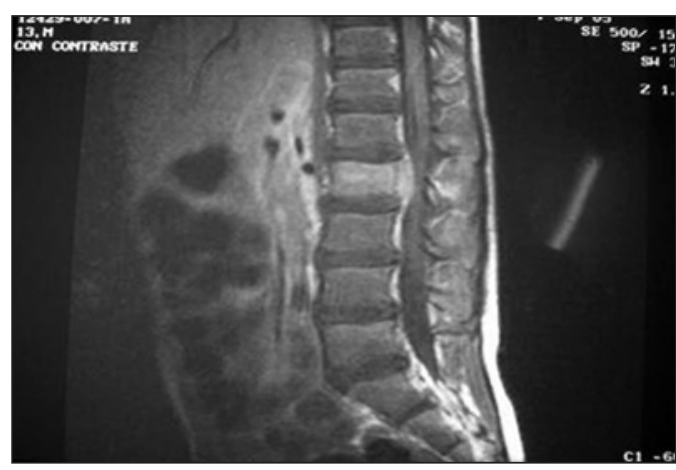

Figura 7. RM de columna vertebral. Proceso sustitutivo del cuerpo de L2 con compromiso de canal y foramen derecho, con indemnidad de los discos interverterales.

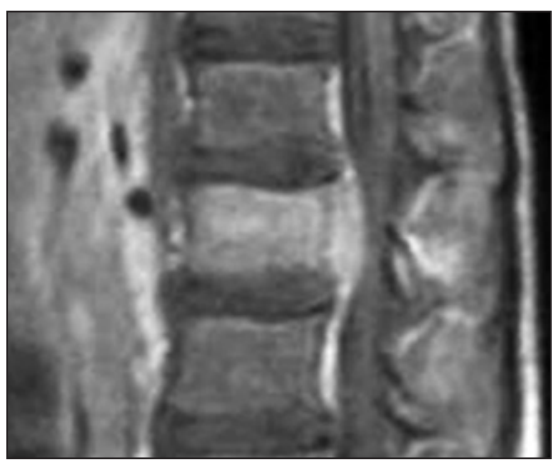

Figura 8. RM de columna vertebral. Imagen ampliada.

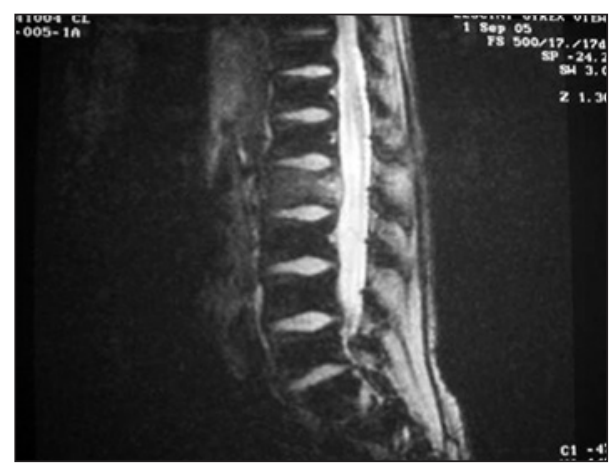

Figura 9. Imágenes de RM ponderadas en T2. Nótese la indemnidad de los discos intervertebrales y el compromiso somático de L2.
Figura 10. A: Biopsia ósea del caso 2. Se observa infiltrado inflamatorio mixto y restos celulares (H-E 600x). B: Coloración de plata de Warthin-Starry; se observan bacilos bien definidos (900x).

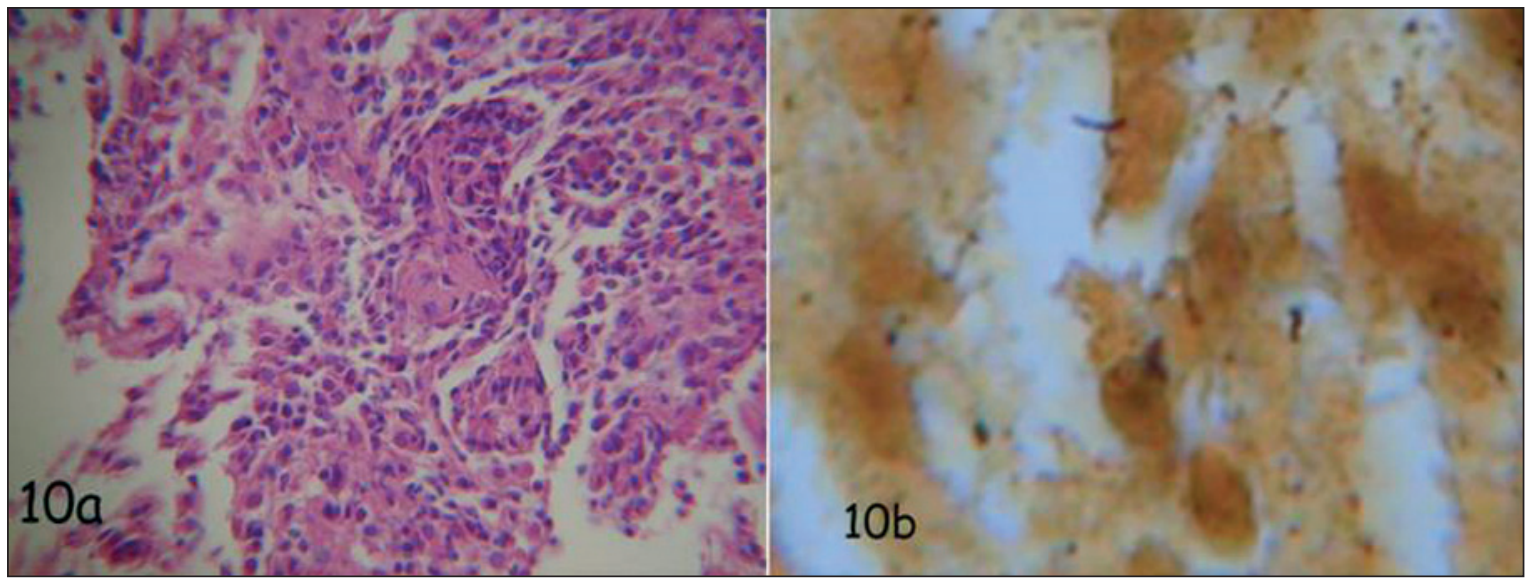

\section{Discusión}

En E.U.A., la incidencia de la EAG se ha estimado en 9,3 casos por 100.000 habitantes $^{1}$. En 1993, el CDC de Atlanta comunicó 22.000 casos nuevos de EAG por año, señalando la existencia de un gran número de casos no diagnosticados ${ }^{6}$. En Uruguay no se dispone de publicaciones relacionadas con esta enfermedad, desconociéndose su prevalencia.

Las características clínicas y los hallazgos de los 
exámenes de laboratorio en ambos pacientes confirman el diagnóstico de EAG en una presentación atípica. Se trata de formas sistémicas, con compromiso hepato-esplénico y óseo, en niños aparentemente sanos e inmunocompetentes. La presentación sistémica es una forma clínica esperable en 5 a $25 \%$ de los $\operatorname{casos}^{1}$; el compromiso óseo es muy poco frecuente habiéndose descrito en $0,3 \%$ de los pacientes ${ }^{7}$.

La EAG atípica es una forma inhabitual de presentación de esta enfermedad; pero la forma hepato-esplénica es un hallazgo frecuente en el estudio del síndrome de fiebre prolongada y dolor abdominal en pediatría. Ocurre generalmente en niños de 2 años a 11 años, con una media de 5 años 5 meses $^{1,8}$. Habitualmente se acompaña de VHS elevada ${ }^{1,8,9}$. Con menor frecuencia, baja de peso, cefalea, fatiga, mialgias, artralgias y lesiones cutáneas ${ }^{3,8,9}$. Los estudios imagenológicos muestran múltiples imágenes hipo-ecogénicas en el hígado o bazo, corresponden a micro-abscesos, al igual que lo observado en estos $\operatorname{casos}^{1,8,9,10}$. Se postula que ocurren por diseminación hematógena ${ }^{8}$. En general tiene un curso benigno, las lesiones se autolimitan al cabo de 1 a 5 meses, describiéndose, en ocasiones, la evolución a calcificaciones ${ }^{9}$.

El compromiso óseo es muy poco frecuente. El primer caso fue descrito en 1954 por Adams y Hindman ${ }^{3}$. Desde 1954 hay publicados en la literatura sólo 34 casos de osteomielitis por $\mathrm{EAG}^{7,11-13}$.

El compromiso óseo generalmente es unifocal, de localización variable, predominando el compromiso vertebral y de cráneo. Menos frecuentemente afecta al hueso ilíaco, fémur, metatarso, metacarpo, esternón, húmero y acetábulo9.

Cuando existe compromiso óseo, las manifestaciones clínicas son similares a las observadas en estos dos casos: fiebre prolongada, baja de peso, dolores óseos, escoliosis si compromete la columna vertebral, pudiendo llegar a la producción de un absceso paravertebral con compromiso infiltrativo y aplastamiento de cuerpo vertebral ${ }^{3}$.

La vía de diseminación del microorganismo al tejido óseo generalmente es hematógena. Esto explica que el foco óseo se ubique usualmente a distancia del sitio de inoculación. Más raramente, el compromiso óseo ocurre por contigüidad ${ }^{11}$.

El cintigrama óseo muestra captación precoz del radiofármaco en las zonas comprometidas, con patrón osteoblástico unifocal o multifocal ${ }^{3}$.

En el caso clínico 2, el compromiso vertebral no cumple con lo clásicamente descrito en las infecciones vertebrales, ya que no presentó compromiso discal y sí del cuerpo vertebral.

La TAC puede mostrar imágenes hipodensas hepatoesplénicas que traducen abscesos, y en el tejido óseo una imagen lítica con halo escleroso y reacción perióstica, similar a lo hallado en este paciente.
La RM es de enorme utilidad en el diagnóstico del compromiso óseo y permite evidenciar imágenes de baja intensidad de señal en T1 e imágenes de alta intensidad de señal en T2 ${ }^{14}$. En el segundo caso analizado, la RM mostró una imagen con aumento de intensidad en T2 que comprometía el cuerpo de la $2^{\mathrm{a}}$ vértebra lumbar, foramen y protrusión hacia el canal raquídeo, destacando la ausencia de compromiso del disco intervertebral. En este caso, y a diferencia de lo observado en infecciones causadas por Staphylococcus aureus, la infección no causó una espondilodiscitis. Bartonella henselae produjo compromiso aislado del cuerpo vertebral; esto determinó la necesidad de realizar una biopsia para confirmar el diagnóstico de osteomielitis. El compromiso óseo plantea diagnósticos diferenciales con tumores malignos, histiocitosis, granuloma eosinófilo, tuberculosis y osteomielitis bacteriana de otras etiologías?

La orientación diagnóstica en los dos casos analizados se basó en la presencia de fiebre prolongada, microabscesos hepato-esplénicos y el antecedente de contacto con gatos. Los métodos de laboratorio que confirman el diagnóstico son estudios serológicos, biología molecular (reacción de polimerasa en cadena - RPC), histología y cultivos. En estos pacientes se utilizó serología más anatomía patológica en el primer caso clínico, y sólo anatomía patológica en el segundo.

Desde 1992, se utilizan métodos serológicos por técnica de IFI o ELISA, que detectan anticuerpos tipo IgG e IgM frente a $B$. henselae ${ }^{8}$. Estos son los métodos más utilizados en la actualidad para confirmar el diagnóstico. Los títulos de $\operatorname{IgG} \geq 1: 125$ (IFI) muestran sensibilidad adecuada para el diagnóstico ${ }^{3}$. En los primeros 10 a 14 días de comienzo de la enfermedad la serología puede ser negativa, desarrollándose posteriormente títulos detectables e inmunidad de por vida. Se describe reacción cruzada entre los antígenos de B. henselae y B. quintana, por lo que carecen de especificidad para el diagnóstico de la especie de Bartonella. Los estudios con técnica de IFI tienen mayor sensibilidad (100\%) y especificidad (98\%) para detección de IgG y los estudios con técnica de ELISA tienen mayor sensibilidad (95\%) y especificidad (77\%) para detección de $\operatorname{IgM}^{1}$. En el primer caso se utilizó IFI y mostró un título elevado de anticuerpos.

La RPC es la prueba más sensible y específica disponible para el diagnóstico. Permite detectar ADN de $B$. henselae en material purulento de ganglio, muestras de biopsia de tejidos o fluidos corporales. Es útil para el diagnóstico diferencial de especies de bartonela, subespecies y cepas ${ }^{3}$.

La biopsia del ganglio linfático o granuloma visceral muestra la lesión histopatológica típica de la EAG. La formación de granulomas con necrosis central, que pueden fusionarse y formar micro-abscesos, constituyen los hallazgos característicos. La tinción de Warthin-Starry o 
las técnicas de impregnación con plata evidencian bacilos pleomórficos en grupos o cadenas cortas en las zonas de necrosis, fácilmente visibles en lesiones tempranas ${ }^{1,15}$. En ambos casos, las biopsias de costilla y vértebra mostraron los hallazgos típicos.

El cultivo de muestras de sangre, ganglios linfáticos y otros tejidos carece de utilidad en la práctica clínica debido a que $B$. henselae es un microorganismo de crecimiento lento en los medios habituales (período de incubación: hasta cinco semanas) ${ }^{1}$.

La intradermoreacción indica exposición previa al agente $y$, dado que la reacción puede persistir durante años, una prueba positiva $(>5 \mathrm{~mm})$ puede no reflejar enfermedad actual; lo que sumado a la existencia de falsos negativos en las primeras tres semanas de evolución de la enfermedad, ha llevado a no utilizarlo actualmente para el diagnóstico ${ }^{1}$

El tratamiento es controvertido. La EAG típica en pacientes inmunocompetentes, en general, es autolimitada y se resuelve espontáneamente en uno a dos meses sin tratamiento específico ${ }^{1}$. Por lo cual es discutida la necesidad de tratamiento antimicrobiano en esta forma de presentación clínica.

En sujetos inmunocompetentes con presentación típica se recomienda emplear azitromicina vía oral durante 5 a 7 días. En un ensayo clínico controlado, randomizado, doble ciego, azitromicina mostró mayor eficacia que el placebo, medida por la velocidad de disminución del volumen del ganglio en el primer mes de tratamiento ${ }^{16}$.

No se dispone de ensayos clínicos controlados evaluando la eficacia del tratamiento antimicrobiano en la EAG atípica9. En una serie de 202 niños, Margileth y cols, comunicaron la eficacia de cuatro antimicrobianos: rifampicina v/o (87\%), ciprofloxacina v/o (84\%), gentamicina intramuscular $(73 \%)$, y cotrimoxazol v/o $(58 \%)^{17}$. Kaplan S y cols, analizaron la eficacia del tratamiento antimicrobiano en 19 pacientes con EAG en su forma hepato-esplénica tratados con gentamicina, rifampicina y cotrimoxazol. Una vez iniciado el tratamiento con rifampicina, sola o asociada, se observó una disminución de uno a cinco días en el período de defervescencia. En base a esta observación se recomienda el tratamiento con rifampicina sola o asociada con gentamicina o cotrimoxazol' ${ }^{9}$.

Otros autores plantean el uso sistemático de antibacterianos en las formas atípicas de la EAG. Los fármacos generalmente recomendados son claritromicina $10-15 \mathrm{mg} /$ $\mathrm{kg}$ /día, rifampicina $10-20 \mathrm{mg} / \mathrm{kg} /$ día, gentamicina $5 \mathrm{mg} /$ $\mathrm{kg} /$ día, cotrimoxazol $40 \mathrm{mg} / \mathrm{kg} /$ día de sulfa (o 6-8 mg/kg/ día de trimetoprim) y ciprofloxacina $20-30 \mathrm{mg} / \mathrm{kg} / \mathrm{día}$ en el niño a partir de los 12 años de edad ${ }^{2}$.

Basados en estas observaciones, se decidió asociar en ambos casos rifampicina $10 \mathrm{mg} / \mathrm{kg} /$ día al tratamiento con ciprofloxacina.

No se han descrito recomendaciones para el tratamiento de las formas con compromiso óseo. Estas generalmente evolucionan a la resolución espontánea en un perÍodo de 4 a 20 meses. En ambos pacientes la evolución fue satisfactoria, curando sin secuelas.

\section{Resumen}

Las manifestaciones clínicas clásicas de la enfermedad por arañazo de gato (EAG) incluyen fiebre, cefaleas, mialgias y adenopatía regional satélite al sitio de inoculación. En 5 a s $25 \%$ de los casos se describen formas atípicas con compromiso sistémico. Se comunican dos casos de niños que ingresan por fiebre prolongada con abscesos hepato-esplénicos Ambos agregan compromiso óseo. En el primero, el cintigrama óseo mostró múltiples zonas de hipercaptación y la serología específica para Bartonella henselae fue positiva ( $\operatorname{IgG}>1 / 256$, IgM positiva débil). En el segundo, la resonancia magnética mostró proceso sustitutivo del cuerpo de L2 con compromiso de canal y foramen derecho, con indemnidad de los discos intervertebrales. En ambos casos, en la biopsia ósea se identificaron bacilos con tinción de Warthin-Starry. Se jerarquiza la búsqueda de esta etiología en niños inmunocompetentes que se presentan con fiebre prolongada y manifestaciones atípicas.

\section{Referencias}

1.- Bass J W, Vincent J M, Person D A. The expanding spectrum of Bartonella infections: II. Cat-scratch disease. Pediatr Infect Dis J 1997; 16 (2): 163-79.

2.- Brenner D J, O’Connor S P, Winker H H, Steigerwalt A G. Proposals to unify the genera Bartonella and Rochalimaea, with descriptions of Bartonella quintana comb nov, Bartonella vinsonii comb nov, Bartonella henselae comb nov, and Bartonella elizabethae comb nov, and to remove the family Bartonellaccea from the order Rickettsiales. Int J Syst Bacterial 1993; 43: 777-86.

3.- Wolff P E, Muñoz F M P, Zapata C, Ledermann W. Enfermedad por arañazo de gato complicada con compromiso sistémico, osteomielitis osteovertebral y absceso paravertebral. Rev Chil Infect 2000; 17: 332-9.

4.- Borker A, Gardner R. Severe thrombocytopenic purpura as a complication of cat scratch disease. Clin Pediatr 2002; 41: 117-8.

5.- Ventura A, Facchini S, Zennaro F, Bussani R, Lenhardt A, Dal Molin G. Clinical Quiz. Case
History. J Pediatr Gastroenterol Nutr 2003; 36: 227- 65.

6.- Schraga E D. Cat-scratch disease. En: http:// www.emedicine.com/emerg/TOPIC84. HTM. Article Last Updated: Mar 6, 2008.

7.- Täger F, Marlis, Zamorano R J. Osteomielitis, una manifestación inusual de la enfermedad por arañazo de gato. Rev Chil Infec 2000; 17: 326-31.

8.- Dunn M W, Berkowitz F E, Miller J J, Snitzer J A. Hepatosplenic cat-scratch disease and abdominal pain. Pediatric Infect Dis J 1997; 16 : 269-72. 
9.- Arisoy E S, Correa A G, Wagner M L, Kaplan S L. Hepatosplenic cat-scratch disease in children: Selected clinical features and treatment. Clin Infect Dis 1999; 28: 778-84.

10.- Modi S P, Eppes S C, Klein J D. Cat-scratch disease presenting as multifocal osteomyelitis with thoracic abscess. Pediatr Infect Dis J 2001; 20: 1006-7.

11.- de Kort Joris, Robben S, Schrander J, van Rhijn L. Multifocal osteomyelitis in a child: a rare manifestation of cat scratch disease. J Pediatr Orthopaedics B 2006; 15: 285-8.

12.- Eckart P, Tournade G, Aminour M,
Guillot M, Courthéoux P, Rousselot P. Maladie des griffes du chat de présentation pseudotumorale. Arch Pédiatr 2001; 8: 393-6.

13.- Ladrón de Guevara D, Lobo G, Miranda M, Wu E, Muñoz M A, Pérez A, et al. Forma atípica de enfermedad por arañazo de gato: Compromiso óseo en dos pacientes pediátricos detectado mediante cintigrafía ósea. Revisión de la literatura. Rev Chil Infect 2003; 20: 202-9.

14.- Heye S, Matthijs P, Wallon J, van Campenhoudt M. Cat scratch disease osteomyelitis. Skeletal Radiol 2003; 32: 49-51.

15.- Cockerell C J, Connor D H. Cat scratch disease.
En: Connor D H, Chandler F W Eds. Pathology of Infectious Diseases. Vol 1. Stamford, Connecticut. Appleton \& Lange. 1997: 461-8.

16.- Bass J W, Freitas B C, Freitas A D,

Sisler C L, Chan D S, Vincent J, et al. Prospective randomized double blind placebo-controlled evaluation of azythromicin for treatment of cat scratch disease. Pediatr Infect Dis J 1998: 17: 447-52.

17.- Margileth A M. Antibiotic therapy for catscratch disease: clinical study of therapeutic outcome in 268 patients and a review of literature. Pediatr Infect Dis J 1992: 11: 474-8. 